\title{
Educação para o Risco: contribuições da complexidade, da reflexividade e das produções socioambientais
}

\author{
Education for Risk: contributions from complexity, reflexivity \\ and socioenvironmental publications
}

\section{Educación para el riesgo: aportes de complejidad, reflexividad y producción socioambiental}

\author{
Fernanda da Rocha Carvalho ${ }^{1}$ \\ Luis David ${ }^{2}$ \\ Carla Sarmento Santos ${ }^{3}$ \\ Fabricio Costa $^{4}$ \\ Gabriel do Prado Cuzziol ${ }^{5}$ \\ Thiago Ceratti ${ }^{6}$ \\ Ricardo Chierecci ${ }^{7}$ \\ Giselle Watanabe ${ }^{8}$
}

\begin{abstract}
Resumo
Os riscos referem-se a um conjunto de situações que nos afetam, sejam eles locais/cotidianos ou mais globais. Para promover uma formação mais crítica e complexa, capaz de lidar com essas incertezas que nossa sociedade impõe, parece essencial delinear um conjunto de parâmetros que definam uma Educação para o Risco. Para isso, este artigo propõe investigar as principais ideias trazidas pelas pesquisas sobre Educação Ambiental, incluindo alguns referenciais teóricos da complexidade e da reflexividade, para, então, delimitar alguns preceitos que definam uma Educação para o Risco, de forma a situá-la e incorporá-la numa formação mais crítica. Metodologicamente, identificam-se os (i) pressupostos teóricos da complexidade e reflexividade e (ii) os aspectos que contribuem para delinear uma Educação para o Risco nos trabalhos sobre Educação Ambiental da área. Para essa análise, toma-se como referência os pressupostos da Análise Textual Discursiva. Dos resultados, nota-se a quase ausência de uma discussão explícita sobre o risco pelos pesquisadores da área; no entanto, é possível identificar alguns aspectos que podem contribuir na delimitação do conceito, tais como a discussão sobre Educação para o Desenvolvimento Sustentável e a busca por uma formação consciente e próxima da realidade do sujeito, e aproximações envolvendo aspectos dos referenciais teóricos que tratam da complexidade, do decrescimento, e da reflexividade.
\end{abstract}

\footnotetext{
${ }^{1}$ Doutoranda em Ensino e História das Ciências e da Matemática; Centro de Ciências Naturais e Humanas, Universidade Federal do ABC (UFABC). E-mail: carvalho.fernanda@ufabc.edu.br

${ }^{2}$ Mestrando em Ensino e História das Ciências e Matemática; Centro de Ciências Naturais e Humanas; professor da educação básica; Universidade Federal do ABC (UFABC). E-mail: luis.david@ufabc.edu.br

3 Mestranda em Ensino e História das Ciências e da Matemática; Centro de Ciências Naturais e Humanas, Universidade Federal do ABC (UFABC). E-mail: carla.santos@aluno.ufabc.edu.br

4 Doutorando em Ensino e História das Ciências e Matemática; Centro de Ciências Naturais e Humanas, Universidade Federal do ABC (UFABC). E-mail: fabricio.masaharu@ufabc.edu.br

${ }^{5}$ Mestrando em Ensino e História das Ciências e da Matemática; pesquisador, Centro de Ciências Naturais e Humanas, Universidade Federal do ABC (UFABC). E-mail: prado.cuzziol@aluno.ufabc.edu.br

${ }^{6}$ Mestrando em Ensino e História das Ciências e da Matemática; pesquisador, Centro de Ciências Naturais e Humanas, Universidade Federal do ABC (UFABC). E-mail: thiago.ribeiro@aluno.ufabc.edu.br

7 Mestre em Ensino de Ciências (Modalidade Física) pelo Instituto de Física da Universidade de São Paulo. Email: ricardo.chierecci@gmail.com

${ }^{8}$ Pós doutora pelo Instituto de Física da Universidade de São Paulo e Universidad de Sevilla/ES; professora do Centro de Ciências Naturais e Humanas da Universidade Federal do ABC, Centro de Ciências Naturais e Humanas, Universidade Federal do ABC (UFABC). E-mail: giselle.watanabe@ufabc.edu.br
} 
Palavras-chave: Ensino de ciências. Educação ambiental. Produções acadêmicas. Complexidade. Educação para o risco.

\begin{abstract}
Risks refer to a set of situations that may affect us, whether they are local/everyday or global risks. In order to promote a more critical and complex formation, enabling us to deal with these uncertainties in society, it seems essential to outline a set of parameters that define Education for Risk. For this aim, this publication intenta is to investigate the main ideas identified by research on Environmental Education, including theoretical references of complexity and reflexivity. On the part of parameters that define an Education for Risk to situate and incorporate it into a more critical formation. Methodologically, it is identified (i) theoretical assumptions of complexity and reflexivity and (ii) the aspects that may contribute to outline an Education for Risk in the publication in the Environmental Education field. For this analysis, the assumptions of Discursive Textual Analysis are taken as a reference. From the results, it is possible to slightly notice absence of explicit discussion about risk by researchers in the area; however, it is possible to recognize some aspects which could outline the concept such as the discussions about Environmental Education and Education for Sustainable Development and the researches for a conscious formation and close to the students' reality, involving approaches of the aspects of complexity, degrowth, and reflexivity theoretical backgrounds.
\end{abstract}

Keywords: Science teaching. Environmental education. Academic production. Complexity. Risk education.

\title{
Resumen
}

Los riesgos se refieren a un conjunto de situaciones que nos afectan, ya sean locales/cotidianos o más globales. Para promover una formación más crítica y compleja, capaz de afrontar estas incertidumbres que impone nuestra sociedad, parece imprescindible trazar un conjunto de parámetros que definan la Educación para el Riesgo. Para ello, este artículo se propone indagar en las principales ideas que aportan las investigaciones en Educación Ambiental, incluyendo algunos referentes teóricos de complejidad y reflexividad, para luego delimitar algunos preceptos que definan una Educación para el Riesgo, con el fin de situarla e incorporarla en una perspectiva más crítica. Metodológicamente, se identifican los (i) supuestos teóricos de complejidad y reflexividad y (ii) los aspectos que contribuyen a perfilar una Educación para el Riesgo en los trabajos de Educación Ambiental en el área. Para este análisis se toman como referencia los supuestos del Análisis Textual Discursivo. De los resultados, hay una casi ausencia de una discusión explícita sobre el riesgo por parte de los investigadores en el área; sin embargo, es posible identificar algunos aspectos que pueden contribuir a la delimitación del concepto, como la discusión sobre Educación para el Desarrollo Sostenible y la búsqueda de una formación consciente cercana a la realidad del sujeto; y enfoques que involucran aspectos de marcos teóricos relacionados con la complejidad, el decrecimiento y la reflexividad.

Palabras-clave: Enseñanza de las ciencias. Educación ambiental. Producciones académicas. Complejidad. Educación sobre riesgos.

\section{Introdução}

Nossa sociedade vive num ritmo acelerado de produção e de consumo de bens materiais para manter um estilo de vida pautado pelas novas tecnologias, que pode ser interpretado como uma necessidade de as pessoas buscarem prazeres imediatos, que promovem situações momentâneas de felicidade. Esse sistema dissemina a ideia de que o consumo de bens materiais é essencial para alcançar o sucesso pessoal, desconsiderando os eventuais riscos imediatos ou futuros que esse consumo pode causar ao meio local ou ao ambiente, de forma mais geral. Os riscos referem-se a um conjunto de situações que nos afetam, sejam elas cotidianas ou mais globais. Em especial, ao tratar das questões socioambientais há, notoriamente, situações implícitas ou explícitas que conduzem a algum risco como, por exemplo, a relação entre o aumento da produção e a disponibilidade de recursos naturais; a desigualdade econômica extrema etc. 
Beck (2010) alerta sobre a dificuldade de se detectar e evidenciar os riscos presentes na sociedade. Ele destaca que, durante a Revolução Industrial, as péssimas condições sanitárias, especialmente os rios de cidades da Europa, eram reconhecidas, pois afetavam diretamente o cotidiano dos europeus. Contudo, nos dias atuais, o conceito de risco torna-se mais abrangente, imbricado e complexo, pois está atrelado aos efeitos diretos ou indiretos à sociedade. Por exemplo, o desmatamento da Amazônia pode ser tomado como uma questão local e direta (que se reverte em rápido retorno financeiro); por outro lado, a longo prazo e indiretamente, ele pode impactar a dinâmica do sistema global, como no regime de chuvas, umidade e temperatura do planeta. Já os desastres ambientais preveníveis, como Mariana e Brumadinho, são exemplos de riscos que afetam, primeiramente, a comunidade local, levando a impactos mais abrangentes como os valores das empresas envolvidas e possíveis boicotes por parte da comunidade mais consciente. Portanto, os riscos e as incertezas estão atrelados a um conjunto de situações de crise que perpassam os âmbitos ambiental, político, social, sociopsicológico, cultural, escolar, cotidiano etc. Como destaca Morin (2020) em suas redes sociais ${ }^{9}$, ao comentar uma das grandes lições da crise da pandemia Covid-19: "não podemos escapar da incerteza, ainda estamos na incerteza da cura do vírus, na incerteza dos desenvolvimentos e nas consequências da crise. Permaneceremos na incerteza da aventura humana" 10 (MORIN, 2020, s.p.)

De modo geral, as questões de natureza socioambiental parecem ser essenciais para uma primeira aproximação à questão do risco. Isso se dá, sobretudo, pela abordagem mais aberta e dinâmica, pautada, também, pelas incertezas que esses temas sugerem. Do nosso ponto de vista, essa discussão deve ser pautada pela perspectiva da complexidade (MORIN, 2007; GARCÍA, 1998; PRIGOGINE; STENGERS, 1992) que integra diversos conhecimentos, ultrapassando uma concepção fragmentada do mundo, buscando o desenvolvimento de um conhecimento escolar complexificado (GARCIA, 1998, 2004) e contribuindo para a construção da criticidade e autonomia do sujeito ${ }^{11}$, tal como salienta Freire (1977).

No Brasil, no contexto dos documentos que orientam a formação escolar básica, dois desses aspectos merecem destaque: a autonomia e a responsabilidade, e as relações entre as áreas do conhecimento. Os Parâmetros Curriculares Nacionais para o Ensino Médio (PCNEM)(BRASIL, 2002) trata a autonomia e a responsabilidade enquanto habilidades essenciais para discutir temas socioambientais relacionados às diversas áreas do conhecimento. Já a Base Nacional Comum Curricular (BNCC) (BRASIL, 2018) discute a importância de o sujeito interagir com o meio ambiente e com os fenômenos naturais ou artificiais, compreendendo suas relações. Apontam para a necessidade de "incorporar aos currículos e às propostas pedagógicas a abordagem de temas contemporâneos que afetam a vida humana em escala local, regional e global, preferencialmente de forma transversal e integradora" (BRASIL, 2018, p.19).

No campo da pesquisa em Educação e no Ensino de Ciências, alguns trabalhos, especialmente preocupados com a Educação Ambiental (EA) no contexto escolar, vêm sendo desenvolvidos nos âmbitos das questões ecológicas/ambientais, por exemplo, nas discussões sobre aquecimento global (CARVALHO, 2016; PERES; SCHENK, 2021); águas (GUERRERO et al., 2021; BUDREVICIUS, 2017); poluição (TAVARES, 2011; BOFF; GOETTEMS; DEL PINO, 2011; DELIZOICOV; ANGOTTI; PERNAMBUCO, 2002); horta

\footnotetext{
9 https://https://twitter.com/edgarmorinparis/status/1241685822107193345 (8:19 AM • Mar 22, 2020·Twitter Web App).

10 Tradução nossa: "Une des grandes leçons de la crise: nous ne pouvons échapper à l'incertitude: nous sommes toujours dans l'incertitude du remède au virus, dans l'incertitude des développements et des conséquences de la crise. Nous resterons dans l'incertitude de l'aventure humaine".

11 Usa-se o termo no masculino, considerando a regra gramatical. Salienta-se que a questão de gênero está contemplada e respeitada nesta produção.
} 
escolar (SANTOS et al., 2021); e os aspectos de natureza social, cultural, política (WATANABE, 2021; LACERDA; STRIEDER, 2019). Mais aliado aos interesses deste artigo e ao campo de pesquisa na área de Educação Ambiental, os trabalhos de García $(1998,2004)$ abordam elementos que caracterizam a EA numa perspectiva mais complexa; o de Latouche (2009) trata das questões socioambientais na perspectiva do decrescimento; e o de Beck (2010) discute aspectos da reflexividade considerando a sociedade de risco.

A partir desse conjunto de ideias, para promover uma formação mais crítica e complexa numa sociedade pautada pelas incertezas, nos parece essencial delinear um conjunto de elementos que definam uma Educação para o Risco. Isso para que possamos buscar ações, nas formações básicas, que levem nossos alunos a se posicionarem criticamente frente às situações reais; por exemplo, aquelas nas quais diversos pontos de vista são levantados ao mesmo tempo em que devem ser prontamente rebatidos, tais como as fake news. Ainda que seja uma primeira aproximação ao tema, essa delimitação se faz essencial para que, no futuro, possamos propor aulas que, efetivamente, analisem e apresentem os riscos nos quais a sociedade, e particularmente os estudantes, estejam envolvidos.

Assim, este artigo propõe investigar as principais ideias trazidas pelas pesquisas sobre Educação Ambiental, considerando, também, aspectos da complexidade e reflexividade, para delimitar alguns parâmetros que definem uma Educação para o Risco. Para tanto, foi realizado um levantamento das pesquisas em Ensino de Ciências e Educação Ambiental, considerando as produções nacionais e internacionais; subsidiados pelos referenciais teóricos da complexidade e reflexividade.

\section{Fundamentação Teórica}

\subsection{Uma educação para a complexidade}

Os aspectos da complexidade tratados neste artigo estão vinculados à EA, ou seja, foi dado espaço vinculado às questões educacionais e escolares dos autores que tratam desse assunto. Nesse panorama, as ideias do biólogo espanhol José Eduardo García Díaz (1998, 2004) contribuem para a reflexão, em especial, por propor mudanças na visão de mundo e nas ações pautadas na construção de um conhecimento escolar com uma natureza epistemológica própria. Ou seja, defende que esse conhecimento se constrói a partir da transição dos conhecimentos cotidiano e científico, como frutos de diferentes processos de formulação, e que podem levar à mudança de um pensamento simples para outro mais complexo. Dessa forma, o discurso voltado à complexidade refere-se à uma reorganização do saber e uma nova forma de atuar e tratar os problemas socioambientais, articulada com outras esferas do conhecimento.

$\mathrm{O}$ autor salienta que a mudança de conduta influencia a ação no meio e para o meio. Considera o rompimento de uma visão de mundo estático e simplista, para a contraposição através de uma nova visão dinâmica e articulada com outras esferas do conhecimento, como as questões sociais, políticas, econômicas e culturais. Ele argumenta que a construção do conhecimento, na perspectiva da complexidade, deve ser um processo baseado na interação, pois possibilita que o indivíduo se torne capaz de tomar decisões, de forma mais crítica, frente à EA como um conhecimento que pode trazer elementos fundamentais na construção de uma outra sociedade, mais complexa e que desenvolva a responsabilidade e a conscientização dos problemas globais e locais.

Uma primeira preocupação com as questões socioambientais recai na busca por um conhecimento escolar (GARCIA, 1998) que possa contribuir para a formação de um sujeito em constante transformação, pois constitui-se como um sistema aberto de ideias que evoluem conjuntamente no tempo. Sendo assim, o conhecimento escolar integra as outras formas de conhecimento e é enriquecido pelos conhecimentos cotidiano e científico, que apoiam, desde 
uma perspectiva mais sistêmica, a continuidade entre as diferentes formas de conhecimento (GARCÍA, 1998). Sob esse mesmo olhar, a EA na perspectiva da complexidade vem ao encontro com o desenvolvimento de uma educação que não seja isolada e particular de uma disciplina, mas pautada em um conhecimento escolar que leve à complexificação (GARCÍA, 1998).

Para o autor, a complexidade apontada não trata, apenas, de uma visão da ciência, mas das relações que se estabelecem no contexto social, político, econômico, cultural etc. Assim, a complexificação do conhecimento escolar traz diferentes preocupações em seu cerne, como a forma de agir e lidar com o meio em transformação, referindo-se à uma reorganização do saber e uma nova forma de atuar e tratar os problemas ambientais de acordo com as esferas do conhecimento. Isso significa considerar a organização dos argumentos dos sujeitos, a interação direta ou indireta dos alunos com o sistema (aula de ciências; escola; cotidiano; professora etc.) e a interação entre esses componentes. Em outras palavras, a complexificação considera a dinâmica do conhecimento, sendo essa uma transição de uma abordagem caracterizada pelos baixos níveis de complexidade, com discursos baseados em seus cotidianos, alcançando níveis mais complexos, nos quais se incorporam aspectos de interação e reorganização do conhecimento escolar.

Considerando a prática da sala de aula nessa perspectiva, Carvalho (2016) demonstra que a construção do conhecimento escolar dos alunos se torna mais complexificada quando há oportunidade para que se aproximem de outras esferas do conhecimento. Logo, o conhecimento escolar não se estabelece de forma contínua e sequencial, mas suas ideias são organizadas ou reconstruídas constantemente, ao longo do processo de ensino aprendizagem, de forma dinâmica e ativa. Salienta-se que essas ideias estão de acordo com a proposta de Morin (2007) ao discutir elementos do pensamento complexo. Para esse autor "complexus significa o que está tecido junto" (MORIN, 1997 apud PETRAGLIA, 2013, p. 17) assim, o pensamento complexo é um tipo de conhecimento que não separa, mas une e busca as relações por um processo de construção e desconstrução, permeado por rupturas e incertezas.

Mais recentemente, essas ideias de García (1998, 2004) foram enriquecidas com reflexões acerca do decrescimento (DIAZ; WATANABE, 2019). A Teoria do Decrescimento trata das questões socioambientais na perspectiva de Latouche (2009), que procura relacionar a mudança de pensamento rumo à redução do consumo ao limite do necessário. $\mathrm{O}$ autor enfatiza a necessidade de abdicação de privilégios pessoais e da acumulação e da abundância, conceitos enraizados na cultura da sociedade moderna. Destaca, também, o combate às necessidades criadas nessa lógica de consumo, que apontam mais para a quantidade do que para qualidade, uma vez que não é possível manter o crescimento infinito do consumo de recursos naturais em um planeta com dimensões e recursos finitos. E argumenta que uma sociedade em decrescimento deverá organizar a produção ao imprescindível para subsistência, fazendo o uso racional dos recursos naturais e o consumo sob forma de bens materiais e de serviços. Enfatizase, ainda, que para o autor o decrescimento não é a negação do crescimento, mas, sim, um distanciamento de uma sociedade de consumo. Vale ressaltar, então, o cuidado que se deve ter ao utilizar o termo decrescimento, pois não se trata de um termo antagônico de crescimento ou de um crescimento negativo.

Em convergência com essas ideias, a EA na perspectiva da complexidade não tem a função de desenvolver determinados hábitos ambientalistas, mas construir um conhecimento escolar pautado na mudança de pensamento e da conduta, que permita ao sujeito compreender a inexistência de uma verdade absoluta sobre a preservação do meio ambiente ou a resolução dos problemas. Essas discussões voltadas para o decrescimento propõem critérios e ações para o desenvolvimento de uma sociedade em harmonia com os limites físicos do planeta. Assim, o desenvolvimento de um conhecimento aberto, dinâmico e integrado possibilita a formação de um cidadão capaz de se tornar consciente e responsável, criando seu próprio saber do mundo. 
Essa formação pode promover reflexões que levem a posicionamentos que sejam revistos e alterados quando novos argumentos mobilizem os sujeitos, tal como salienta Beck (2010) ao tratar da reflexividade e da sociedade de risco.

\subsection{Uma educação para a reflexividade e os riscos}

Ao pensar em uma formação mais crítica e complexa, um dos elementos centrais está no estabelecimento de um ensino voltado para a proposição de um cidadão político e socialmente responsável. Isso, de certo modo, leva à uma educação capaz de estimular a participação dos estudantes em uma sociedade permeada por situações reais, na qual os diferentes riscos estão colocados. De acordo com Beck (2010), em vista de uma formação do indivíduo para se posicionar frente aos problemas de uma sociedade pautada no risco, deve haver a construção das relações e das interferências sociais e históricas que existem em uma sociedade moderna.

Ainda que não relacionado diretamente à educação, é possível aproximar esses preceitos das reflexões na esfera educacional, tendo como base a reflexividade (WATANABE, 2021)(WATANABE; KAWAMURA, 2014). Assim, a educação para a reflexividade refere-se à possibilidade de repensar e reconstruir posicionamentos, de forma que surja um conjunto de ideias que se reorganizam para, então, subsidiar um posicionamento frente às situações da realidade (BECK, 2010; FREIRE, 1977). Esse posicionamento não é fechado e tampouco estagnado. Ele é dinâmico e pode ser reconstruído para se ajustar às novas aprendizagens. Evidentemente, essa forma de pensar e agir não deve subsidiar os discursos frágeis que buscam interesses particulares, por exemplo, aqueles que se pautam em promessas políticas que são modificadas logo após alcançar um objetivo específico.

Tratar as questões socioambientais do ponto de vista de uma EA pautada na reflexividade remete à preocupação com ameaças e riscos tão presentes no processo de modernização, que inclui a problemática de distribuição de conflitos e escassez que são produtos do progresso científico e tecnológico da sociedade atual (BECK, 2010). Para o autor, o desenvolvimento da sociedade avança junto com a distribuição de riqueza e os riscos que nela despontam. Para ele,

[...] não se trata mais, portanto, ou não se trata mais exclusivamente de uma utilização econômica da natureza para libertar as pessoas de sujeições tradicionais, mas também e sobretudo de problemas decorrentes do próprio desenvolvimento técnicoeconômico. O processo de modernização tornou-se "reflexivo", convertendo-se a si mesmo em tema e problema (BECK, 2010, p.23).

Mas como definir risco? Os riscos envolvem um conjunto de situações cotidianas ou mais globais. Estão presentes em quaisquer ações que podem ser tomadas a depender do olhar de cada sujeito. Tem, portanto, uma vertente muito individual: o que para alguns é um alto risco, para outros pode ser insignificante. Contudo, quando se trata de riscos globais, há de se considerar que afetam a coletividade e podem atingir um bem maior. Por exemplo, lidar com os efeitos das mudanças climáticas ou as pandemias requer que a coletividade tenha clareza sobre os riscos que os envolvem, individual e coletivamente, para, então, promover ações efetivas, em conjunto. Vale destacar que o termo risco para Beck (2010) está atrelado ao desenvolvimento científico e tecnológico que, por sua vez, pode contribuir para o agravamento dos problemas socioambientais, tais como os riscos ecológicos ou decorrentes dos processos nucleares.

Ele salienta que os riscos produzidos na economia e na política são ameaças para a modernidade, assim, qualquer produção de riqueza é associada a um risco, acarretado de alguma etapa do processo de criação da riqueza, como obtenção de matéria-prima, desenvolvimento de 
um produto ou distribuição de algum bem. Para o autor, a modernização reflexiva traz uma discussão em torno de um caminho que leve os indivíduos a compreender o mundo de uma forma menos determinista e reducionista, considerando os riscos e as incertezas inerentes nas tomadas de decisão. A modernização reflexiva, então, "significa a possibilidade de uma (auto)destruição criativa para toda uma era: aquela da sociedade industrial. O 'sujeito' desta destruição criativa não é a revolução, não é a crise, mas a vitória da modernização social" (BECK; GIDDENS; LASH, 1997, p. 12).

Dessa leitura, analisar as questões socioambientais sob a perspectiva da reflexividade exige o cuidado em se compreender as relações e as interferências presentes em uma sociedade como a nossa. Os problemas socioambientais não têm uma resposta única, mas diversas possibilidades de soluções, quando analisados sob distintas perspectivas. Por isso, Beck (2010) defende a modernização reflexiva, sendo uma ação centrada nos processos de inter-relações, baseada nas incertezas e no dinamismo.

Ao tratar do risco no contexto da educação, destaca-se o documento orientador de discussões na educação Pré-Escolar, Ensinos Básico e Secundário em Portugal, denominado Referencial de Educação para o Risco (RERisco, 2015). O RERisco salienta a necessidade de estabelecer uma abordagem curricular sobre os riscos a partir do olhar da comunidade, procurando conscientizar a sociedade sobre as estratégias de conhecimento para as prevenções desses riscos, estabelecendo uma cultura de segurança e de resiliência. De modo geral, o documento propõe como objetivos: sensibilizar a comunidade educativa para a temática da proteção civil; identificar os riscos; adquirir hábitos de segurança e desenvolver competências no âmbito da proteção civil; promover atitudes e comportamentos adequados em situações de emergência; promover os planos de segurança internos face aos riscos; e promover a segurança pessoal. $\mathrm{O}$ documento destaca que

[...] importa prosseguir os esforços para que a educação, a formação e a informação se situem nos patamares superiores da hierarquia dos objetivos das políticas públicas neste domínio, estimulando e promovendo o ambiente propício ao envolvimento dos indivíduos, na proteção das suas comunidades e na preservação dos bens comuns (RERisco, 2015, p. 8).

O RERisco enfatiza a necessidade da mudança de comportamento e de atitude das crianças e dos jovens frente aos problemas da comunidade, ressaltando a importância de conhecer o risco, identificar as causas e os efeitos, e estabelecer medidas de autoproteção. Diante disso, Jacobi (2005, p. 15) defende que a "sociedade sustentável se fortalece na medida em que se desenvolvam práticas educativas", sendo a escola um espaço essencial para o sujeito torna-se atuante diante dos problemas socioambientais.

Uma EA nessa perspectiva deve reconhecer a impossibilidade de discutir tais questões de forma reducionista e linear. Isso significa ter clareza de que nem todos os problemas e as questões socioambientais estão explícitos, assim como as relações que nele e dele se estabelecem, tal como salientam Watanabe e Kawamura (2014, p. 8): " ainda que conseguimos, com certa limitação, identificar alguns dos riscos iminentes numa sociedade, somos incapazes de apontar com clareza os verdadeiros responsáveis pelo agravamento da crise ambiental e pela promoção de riscos (WATANABE; KAWAMURA, 2014, p. 8).

Por fim, há de se considerar que os fatores associados a um risco são, frequentemente, relacionados a várias áreas do conhecimento, como Biologia, Física ou Sociologia, visto que a realidade é interligada e dinâmica. Nessa perspectiva, uma EA na perspectiva da reflexividade pode promover uma educação que reconheça e identifique a formação de novos riscos com potencial para afetar nossa sociedade de forma local e global, estabelecendo as relações sociais e assumindo a participação do sujeito no processo de desenvolvimento da sociedade.

\section{Metodologia}


Para este artigo, foi realizado no GrECC $^{12}$ (Grupo de Ensino de Ciências e suas Complexidades) um levantamento das pesquisas em Ensino de Ciências e Educação Ambiental, assim como estudo dos referenciais teóricos. Especificamente, este estudo consta de dois momentos, a saber: em (A) analisam-se as ideias que definem a complexidade e a reflexividade de García (1998, 2004) e Beck (2010), com a intenção de articulá-los com os resultados que levam aos parâmetros que caracterizam uma Educação para o Risco; em (B) analisam-se os dados obtidos a partir do levantamento bibliográfico de artigos publicados no período de 2014 a 2019 na área da Educação e do Ensino de Ciências.

A análise dos dados em (B) ocorreu em dois momentos. No primeiro, foram analisados 229 trabalhos publicados em revistas e congressos, no período delimitado entre 2014 a 2019 . O procedimento para a coleta do material se deu através da consulta nos sites das revistas e dos anais dos congressos, tomando como referência para a análise as palavras-chave, nos títulos dos trabalhos e nos resumos, como: educação (socio)ambiental; ambiente; educação sustentável (para a sustentabilidade); desenvolvimento sustentável. No segundo momento, as produções analisadas com mais profundidade, a partir do levantamento anterior, ficaram adstritas ao período de 2018 e 2019, compondo um universo de 54 produções.

A análise se deu de forma mais refinada, com a leitura do texto na íntegra orientado pelas subpalavras: complexidade, percepção ambiental; risco, pensamento crítico, decrescimento; vulnerabilidade; catástrofes; controvérsia/questão sociocientífica, ecologia; temas com foco socioambiental (poluição/ contaminação/ disponibilidade de energia, água, ar; biodiversidade; mudanças climáticas).

Para ambos os momentos, foram analisadas oito revistas da área da Educação e do Ensino de Ciências, a saber: Ensenanza de las ciências; Investigações em Ensino de Ciências; Environmental Education Research; Revista Ensaio; Ambiente \& Sociedade; Caderno Brasileiro de Ensino de Física; Ciência e Educação e Revista Electrónica de Enseñanza de las Ciencias. Foram analisados, igualmente, trabalhos publicados em quatro congressos das mesmas áreas, a saber: Encontro Nacional de Ensino de Biologia (ENEBIO); Encontro de Pesquisa em Ensino de Física (EPEF); Simpósio Nacional de Ensino de Física (SNEF) e Encontro Nacional de Pesquisa em Educação em Ciências (ENPEC). Salienta-se que, para a revista Ciência e Educação e o congresso do ENEBIO, a análise se concentrou apenas nos trabalhos apresentados nos últimos quatro anos (eventos de 2016 a 2019), devido ao grande volume das produções em Educação Ambiental. A opção por essas revistas e eventos refletem os espaços conquistados por eles no quesito divulgação e discussão acerca das pesquisas nacionais e internacionais de ponta na área, além disso, procurou-se contemplar aquelas com melhores ranqueamentos de Qualis A e B; quanto ao período, considera-se o recorte de seis anos para contemplar eventos desenvolvidos em anos pares (2014, 2016 e 2018) e ímpares $(2015,2017$ e 2019).

As informações obtidas seguiram os pressupostos da Análise Textual Discursiva (ATD) (MORAES; GALIAZZI, 2007), que se divide em três etapas: unitarização, categorização temática e comunicação. Essas fases levam o pesquisador a construir novos caminhos para a compreensão dos fenômenos estudados, e são construídas ao longo do processo de análise, de forma recursiva, emergindo novos entendimentos. A unitarização se desenvolve a partir da realização da fragmentação de trechos dos estudos que fazem referência, implícita ou explícita,

12 O Grupo de Ensino de Ciências e sua Complexidades (GrECC) articula a complexidade ao Ensino de Ciências/ Física e a Educação Ambiental. Esse grupo é parcialmente financiado pela Fundação de Amparo à Pesquisa do Estado de São Paulo (Fapesp) (processo no2018/19136-3); e pelos Ministério da Ciência, Tecnologia, Inovações e Comunicações (MCTIC) e o Conselho Nacional de Desenvolvimento Científico e Tecnológico (CNPq) (chamada 05/2019, processo $\left.\mathrm{n}^{\circ} 440369 / 2019-3\right)$. 
a elementos que apresentam relação com a perspectiva de complexificação do conhecimento (GARCÍA, 1998) e aspectos da reflexividade (BECK, 2010).

Ao analisar as produções sob essa perspectiva teórica, emergiram as categorias temáticas, configurando a segunda etapa da ATD, a saber: K1 - propostas que tratam da questão socioambiental e que tem um viés educacional de Ensino de Ciências (formal, não formal e informal), incluindo as propostas e atividades para sala de aula; K2 - indicadores gerais (parâmetros, gestão democrática/ participativa), documentos oficiais/ políticas públicas; K3 formação de professores (relatos e proposições) que pode ocorrer no âmbito de cursos de graduação, pós graduação, formação continuada da escola básica e cursos de extensão; K4 análise de ideias dos alunos, professores e grupos específicos envolvidos com o Ensino de Ciências (comunidade, gestores etc.); K5 - teóricos, incluindo estado da arte, análise de eventos, revistas, periódicos, dissertações, teses e afins; K6 - análise de materiais didáticos e paradidáticos com foco no Ensino de Ciências. Como etapa final, a comunicação se desenvolveu pela elaboração de textos descritivos e interpretativos (metatextos) acerca das categorias temáticas a partir das etapas anteriores; no nosso trabalho isso é apresentado nos resultados que delimitam alguns parâmetros para a Educação para o Risco.

\section{Apresentação dos dados: apontamentos e preocupações sobre a EA nas produções}

O levantamento realizado no primeiro momento trouxe uma visão geral das produções na área de Ensino de Ciências e Educação, no período de 2014 a 2019. Nas produções desse período mais abrangente, nota-se que $21 \%$ dos trabalhos analisados estão voltados a $\mathrm{K} 1$, que propõe atividades, projetos e práticas educativas para o contexto da educação. Na K2 encontram-se $15 \%$ dos artigos, que apresentam mudanças nos currículos e análise de documentos que balizam a educação. Já na categoria K3, cerca de $10 \%$ artigos estão preocupados em discutir a implementação de ações na formação inicial ou continuada de professores, visando o trabalho com temas voltados às questões socioambientais. Em K4, com $32 \%$ dos artigos, encontram-se os trabalhos que discutem as concepções dos alunos e professores sobre os assuntos voltados ao meio ambiente. Em K5, com 15\% dos trabalhos, encontraram-se artigos preocupados em discutir referenciais teóricos ou conceitos e formulações de Física que dão suporte para o debate das questões ambientais. Em K6, os resultados apontam para 7\% das produções voltadas à análise de material didático que aborda questões socioambientais.

A relação entre a quantidade de artigos publicados durante seis anos e as categorias pode ser observada na Figura 1. 
Figura 1 - Distribuição das produções no período mais amplo (2014-2019)

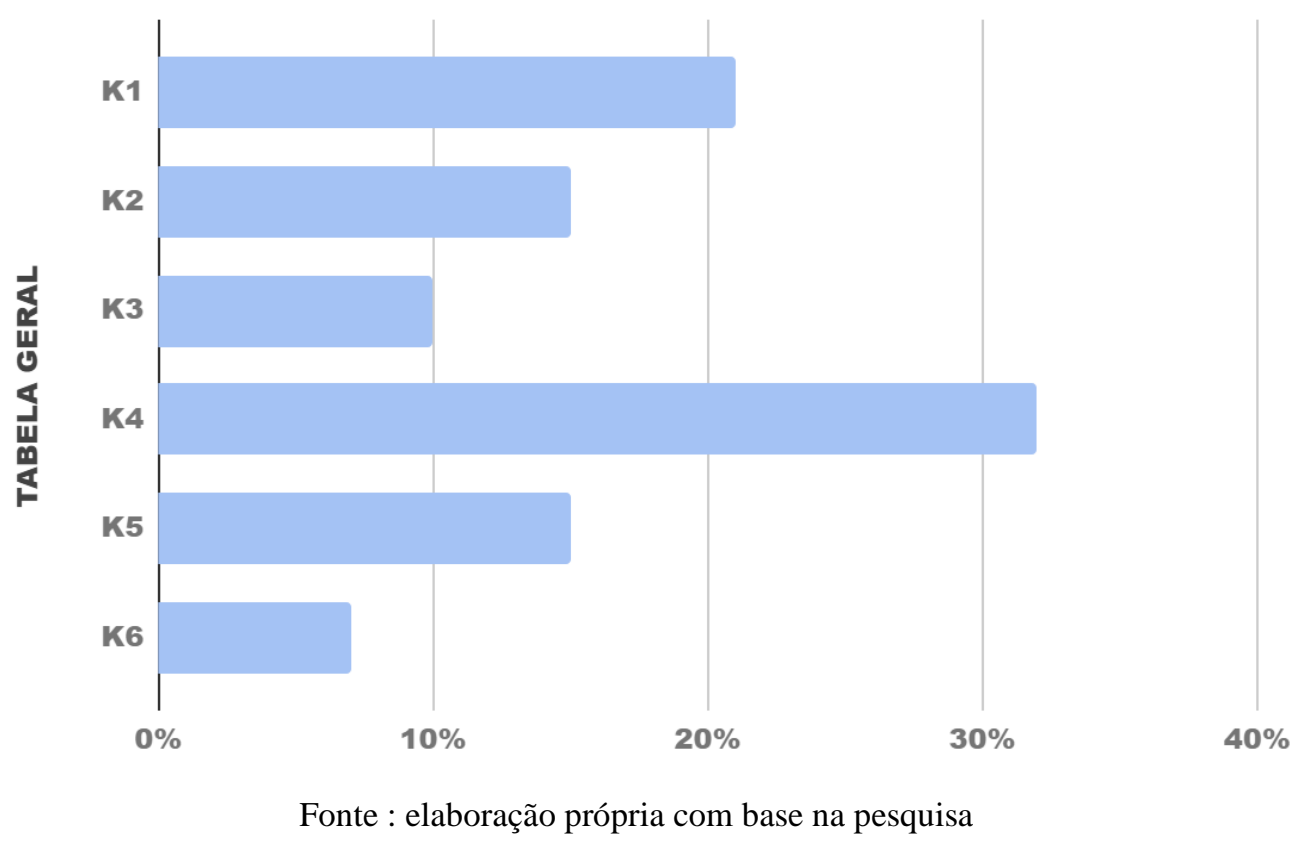

Esses números indicam que os trabalhos encontrados estão centrados às concepções de alunos e professores e carecem de uma atenção quando as produções são voltadas para análises de materiais didáticos. Vale ressaltar que os dados do K1 e K6 convergem para a categoria K4. Nota-se que muitos trabalhos elaboram atividades (K1) ou analisam materiais (K6) para os alunos (ensino fundamental, médio ou superior) ou professores (rede pública ou particular), o que explica sua alta porcentagem na categoria K4.

Quanto à análise mais aprofundada, que contempla o segundo momento (2018 e 2019), buscou-se compreender as discussões sobre EA abordadas pelos autores dos trabalhos. Vale ressaltar que foram consideradas as diferentes visões de mundo, associadas às questões sociais, culturais, políticas e econômicas de cada autor. O Apêndice $1^{13}$ traz as produções acadêmicas do período de 2018 a 2019, identificadas como T1,..., Tn. Esses artigos estão distribuídos da seguinte forma: $28 \%$ em K1, $5 \%$ em K2, $17 \%$ em K3, 29\% em K4, 17\% em K5 e 4\% dos artigos em K6. Comparando com os dados da primeira análise, é possível identificar que os extremos (alta e baixa porcentagem) das produções em K4 e K6, respectivamente, se mantém. Ou seja, a partir de análises tanto gerais quanto específicas dos dados, a perspectiva se mantém, reforçando a necessidade de se desenvolver mais trabalhos contextualizados nas outras categorias.

Uma análise mais ampla das categorias indica que, em $\mathrm{K} 1$, os trabalhos estão preocupados com a prática para promover a participação do sujeito e a diversidade de materiais para trabalhar com EA, convergindo para a realidade local do aluno, junto com a tomada de consciência frente ao problema ambiental. Por exemplo, o T93 menciona que as discussões da EA possuem tantas correntes e linhas de pesquisas que necessitam ser mais específicas na área do ensino para conduzir uma prática mais efetiva, deixando transparecer a preocupação em delimitar propósitos de formação mais crítica. T76, T78 e T181 argumentam que propostas de ensino ou projetos devem visar a aprendizagem significativa e incorporar a participação dos indivíduos. T103 apresenta como uma alternativa a elaboração de materiais didáticos, audiovisuais ou impressos considerando a realidade local de cada grupo. Sobre isso, T106

${ }^{13}$ Os artigos podem ser encontrados, na íntegra, no site: https://sites.google.com/view/greccufabc/produções/artigos 
utiliza da confecção de HQs como uma alternativa de material com linguagem adequada para os jovens.

Em K2 os trabalhos apontam para os aspectos de uma educação para o desenvolvimento sustentável na tentativa de promover uma consciência ambiental no contexto escolar como exercício para a cidadania; além de indicar uma EA mais complexa, menos determinista e simplificadora. Por exemplo, o T147 discute a importância de trabalhar as questões socioambientais na escola, uma vez que este é um espaço propício para promover a consciência ambiental. Nesse sentido, T147 discute a diferença entre educação para o desenvolvimento sustentável e educação ambiental. $\mathrm{O}$ autor defende a necessidade de que se tornem uma disciplina escolar. T208 se aproxima do T147 ao trazer um apanhado histórico das discussões entre educação e questões socioambientais. Destacam que a EA pode ser diversa, e refletem sobre esses caminhos ao longo do texto, apontando a EA como exercício de cidadania, desde que seja crítica. T209 traz versões de EA a partir de documentos e leis brasileiras e espanholas que tratam da temática.

Em K3 estão os trabalhos que colocam a EA como uma dimensão fundamental na formação de professores e discutem a necessidade de uma reformulação metodológica, conceitual e curricular nos cursos de formação de educadores ambientais. Esses textos salientam que as atividades práticas são ferramentas fundamentais para promover uma aproximação maior dos alunos com os temas ambientais, fazendo com que o trabalho do educador ambiental seja mais significativo e efetivo. Por exemplo, T31 enfatiza a abordagem crítica na EA que, por sua vez, pode atuar na formação ecológica do cidadão e pode valorizar as discussões com características político-ideológicas sobre temas ambientais. T207 destaca que a EA não está fechada em um conjunto de teorias e práticas, apontando que há, pelo menos, duas grandes tendências denominadas EA crítica e EA conservadora, a qual preserva características hegemônicas. T197 discute a postura do professor como pesquisador e um profissional reflexivo. Nessa mesma linha, T99 propõe e discute a inserção de uma disciplina de Educação Ambiental como componente curricular, justificando que a inclusão de uma disciplina específica amplia e dá base teórica aos professores em formação.

Em K4 estão os trabalhos preocupados com as percepções acerca da sustentabilidade e da EA; além dos que tratam de uma EA pautada em um sistema que considere a importância da conservação do ecossistema. Por exemplo, T4, T102 e T223 tratam da percepção docente acerca da sustentabilidade e EA. No geral, há a predominância de uma visão mais naturalista (ambiente como meio); além disso, os trabalhos demonstram a insegurança dos profissionais da educação em tratar o tema. Em T82, T100 e T166 há orientações para uma perspectiva de trabalho local e preocupação com a literatura, propondo visitas aos espaços não formais de educação e questionando políticas sobre descarte, saneamento entre outras ações. Esses trabalhos também tratam a EA a partir de um sistema que compreende a importância da conservação do ecossistema ao seu redor. T30 e T90 consideram uma percepção ambiental mais ampliada dos sujeitos envolvidos, mais integrada dos processos, passando a se perceber como integrantes de um ambiente amplamente diversificado, e cuidando das fontes de informação.

Em K5 estão as produções que relacionam a sustentabilidade ao desenvolvimento sustentável, propondo um olhar mais crítico sobre o alarmismo catastrófico e a busca pela conscientização ambiental. Por exemplo, T83 destaca o crescente número de produções relacionadas à EA no Brasil, ao longo dos últimos anos, salientando que há um crescimento das produções relacionadas à sustentabilidade e ao desenvolvimento sustentável. T95 acaba por discorrer sobre aspectos que impactam na EA, como a mídia e o alarmismo catastrófico criado por ela. O texto traz uma crítica ao tipo de EA que se quer utilizar nos dias de hoje. T96 busca frisar a conscientização ambiental por meio do evento Green Day, com o objetivo de constituir um diálogo com a comunidade por meio das diversas abordagens da EA. 
Em K6 estão os trabalhos que discutem a interdependência econômica, social, política, cultural e ecológica; assim como aqueles que buscam uma EA capaz de reinventar a maneira de explorar o ambiente. Por exemplo, T74 discute a forma com a EA possibilita a compreensão da interdependência econômica, social, política, cultural e ecológica, proporcionando à humanidade o meio de construir novos conhecimentos que propiciem uma mudança de atitudes e comportamentos. T81 discute, do ponto de vista social e cultural, o poder do homem em explorar a natureza livremente, sem culpa e de forma demasiada, visto que o atual sistema econômico baseado na geração de riqueza mantém os níveis de exploração maiores que o meio ambiente pode suportar. Para os autores, a EA deve transformar a forma de produção e consumo econômico no âmbito da sociedade contemporânea.

\section{Resultados: o que os referenciais teóricos e as produções atuais nos mostram sobre a Educação para o Risco}

Ao realizar a leitura dos referenciais sobre complexidade e reflexividade e identificar as principais características das pesquisas em EA foi possível levantar um conjunto de parâmetros, ainda que restritos, que podem nos ajudar a delinear a Educação para o Risco. A opção por destacar aspectos advindos dos estudos dos referenciais teóricos se dá por conta da ausência desses aspectos indicados pelos autores na pesquisa realizada a partir das produções da área. Dos resultados desse trabalho destacam-se, tal como sistematizado na Figura 2, alguns dos elementos que deveriam/poderiam prescindir das ações educacionais voltadas às aprendizagens mais abertas e próximas da realidade do sujeito (FREIRE, 1977), dando margem para tratarmos dos riscos e incertezas. Nota-se que, na Figura 2, as cores azul e vermelho trazem um resgate sucinto do referencial teórico discutido na primeira seção, já a cor verde destaca as principais interpretações sobre educação ambiental encontradas ao longo da análise de cada categoria. 
Figura 2 - Alguns parâmetros que podem definir uma Educação para o Risco

\section{Perspectiva da Complexidade}

- o conhecimento escolar tem sua própria natureza - construído a partir da transição dos conhecimentos.

- buscar a transição de um pensamento simples para outro mais complexo.

- buscar a visão dinâmica e articulada com outras esferas do conhecimento.

- a construção do conhecimento que deve ser processo baseado na interação.

- formação em constante transformação, pautada em um sistema de ideias aberto e que evolui no tempo.

- complexificação do conhecimento.

- pensamento complexo.

- redução do consumo considerando o tempo de reorganização do meio (decrescimento).

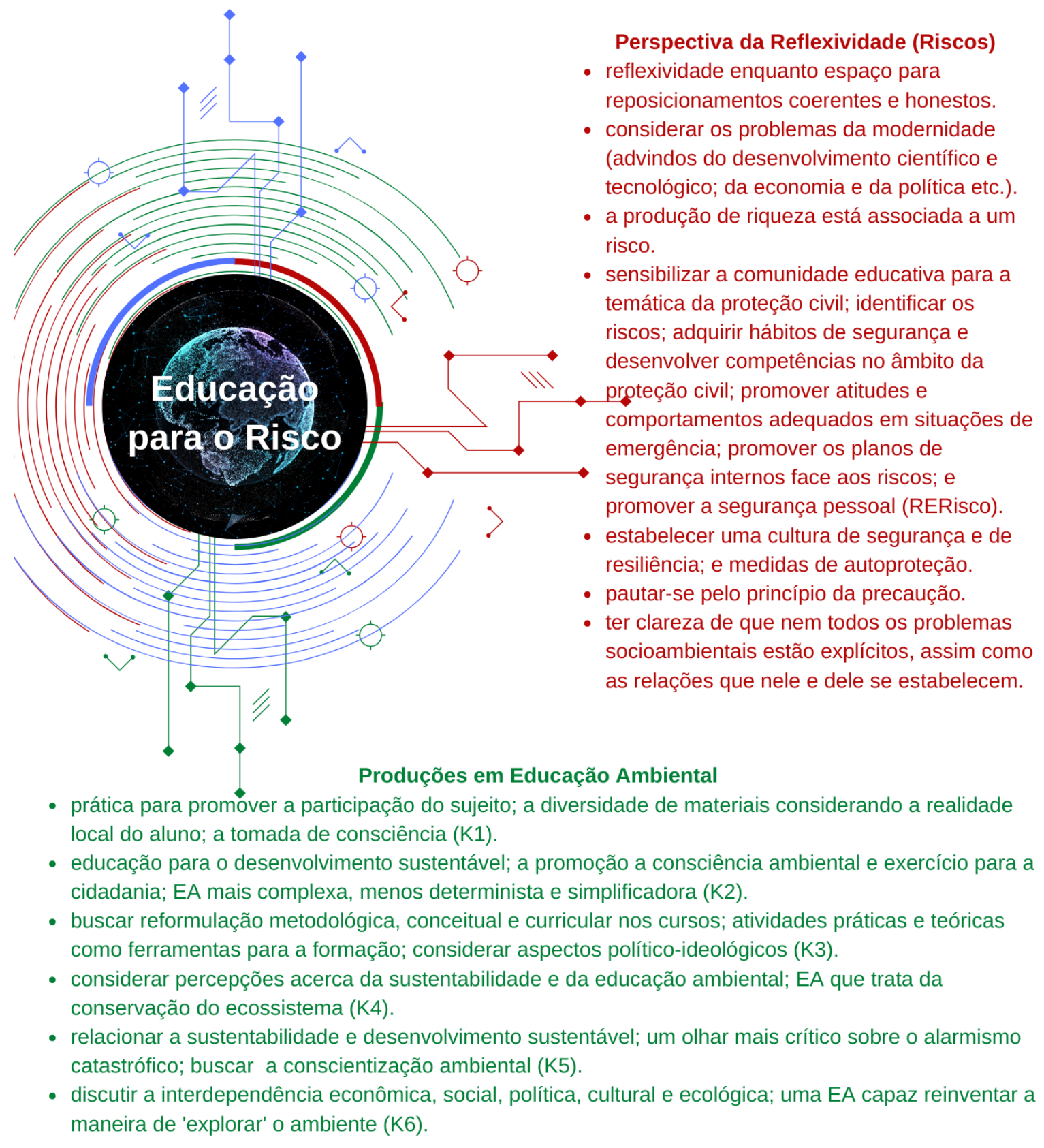

Fonte: elaboração própria com base na pesquisa 
Das contribuições da perspectiva da complexidade, um dos aspectos centrais volta-se ao conhecimento escolar resguardado de sua própria natureza, ou seja, é um conhecimento que deve ser aceito a partir de suas próprias características, sem que esteja subordinado aos outros conhecimentos. Assim, o conhecimento escolar deve ser construído a partir da transição dos conhecimentos cotidiano e científico e de outras esferas (arte, cultura etc.). Essa concepção leva à compreensão de que o sistema de ideias não pode ser somente simplificador/reducionista/ determinista (MORIN, 2007; PRIGOGINE; STENGERS, 1992), e que há de se considerar romper com a visão de mundo estática, buscando uma perspectiva mais dinâmica e articulada com outras esferas do conhecimento (científico, cotidiano, artístico, tecnológico, cultural etc.). Trata-se, portanto, de buscar a transição de um pensamento simples para outro mais complexo, o que remete às considerações do conceito de pensamento complexo (MORIN, 2007).

Ainda na perspectiva da complexidade, há de se considerar que a construção do conhecimento é um processo baseado na interação, seja com o meio, com os sujeitos, com outras formas de conhecimento, entre outros. Nesse sentido, a formação dos indivíduos também está em constante transformação e apresenta um sistema de ideias aberto e que evolui, conjuntamente, no tempo. No contexto escolar, a proposta de complexificar o conhecimento pode contribuir com a formação desejada. Tratar a sala de aula e a aprendizagem dos alunos de maneira mais aberta, e considerando que as ideias evoluem de forma complexa e pouco estável, dá margem para que os docentes possam entender e aceitar as limitações e os espaços possíveis de intervenção efetiva. Para tal, cabe pensar em outros elementos, como os níveis de formulação e níveis de progressão (RODRÍGUEZ-MARÍN; FERNÁNDEZ-ARROYO; GARCÍA, 2014; CARVALHO; WATANABE; RODRÍGUEZ-MARÍN, 2015; CARVALHO, 2016). Por fim, uma Educação para o Risco, nessa perspectiva, pode ter aproximações com ideias sobre o decrescimento, em especial, com a que trata da mudança de pensamento visando promover atitudes de redução do consumo, considerando o tempo de reorganização do sistema (ambiente).

Das contribuições da perspectiva da reflexividade e de alguns referenciais que abordam a questão dos riscos, destaca-se a possibilidade de os sujeitos se posicionarem ao reconstruir suas ideias quando, no decorrer das aprendizagens, tenham maiores esclarecimentos, mais coerentes e honestos. Esse é o conceito da reflexividade que traz a possibilidade de um trabalho escolar mais aberto e dinâmico do ponto de vista de sua construção e reconstrução. Destaca-se que esse dinamismo não é porta de entrada para o oportunismo, como já salientado anteriormente. Outro aspecto refere-se aos problemas e aos riscos advindos do desenvolvimento científico e tecnológico, da economia e da política. Essas são ameaças, visto que se tornam tanto um tema a ser tratado quanto um problema a ser estudado. Vinculada a essa ideia há, ainda, a necessidade de discutir a produção de riqueza enquanto uma produtora de risco. Em outras palavras, em uma sociedade como a nossa, produzir bens e riquezas também implica em produzir diversos riscos.

Esses elementos, que trazem um panorama sobre a produção de riscos, também podem dar oportunidades para discutir as formas de agir. Assim, buscar ações como sensibilizar a comunidade educativa para a temática da proteção civil; identificar os riscos; adquirir hábitos de segurança e desenvolver competências no âmbito da proteção civil; promover atitudes e comportamentos adequados em situações de emergência; promover os planos de segurança internos face aos riscos e promover a segurança pessoal são ações que podem contribuir para uma formação em que aspectos da cultura de segurança e de resiliência, do estabelecimento de medidas de autoproteção sejam contemplados.

Essas preocupações remetem, também, ao princípio da precaução, que se pauta em ações discutidas e bem articuladas que antecedem o problema. Ou seja, identificar possibilidades de antecipar os problemas e agir sobre eles antes que ocorram, são aspectos que levam a uma formação mais centrada, mais crítica e complexa. Por fim, é fundamental estabelecer um 
diálogo em que se tenha clareza de que nem todos os problemas decorrentes das questões socioambientais serão explicitados, assim como as relações que nele e dele se estabelecem. Pois, há de se considerar as incertezas inerentes ao sistema e, diante deles, ainda assim, há de se posicionar criticamente.

Das contribuições das produções acadêmicas em EA destacam-se a preocupação com uma educação para o desenvolvimento sustentável e a formação de um sujeito mais ativo socialmente. Os elementos encontrados nas categorias, quando próximas às perspectivas da complexidade de reflexividade, foram indicados como aqueles que contribuem para definir uma Educação para o Risco. Especificamente, os trabalhos em K1 apontam para a importância da diversidade dos materiais e das práticas em sala de aula para, então, promover a participação do sujeito em sua realidade, aproximando-se de ações complexificadas, como a construção de hortas escolares (GARCIA, 2004; SANTOS et al., 2021).

Em K2, as produções indicam a necessidade de considerar os aspectos da EA para tratar do desenvolvimento sustentável. Apontam que isso seria a chave para manutenção de uma sociedade sustentável, pautada por ações mais globais e que abranjam tanto a educação formal quanto a informal. Pontualmente, alguns autores consideram a importância de que a EA seja uma disciplina curricular, no entanto, a abordagem mais recorrente sinaliza para uma formação capaz de incorporar elementos de outras esferas do conhecimento, identificando as dificuldades diante das questões ambientais através dos interesses políticos, culturais e sociais da comunidade. Destaca-se, ainda, que a educação para desenvolvimento sustentável incorpora aspectos para a promoção da consciência ambiental no contexto escolar como exercício para a cidadania. Essa questão é desenvolvida, com grande destaque, no currículo escolar português, especialmente por meio de projetos interdisciplinares (RERISCO, 2015).

Em K3 as produções repensam uma reformulação metodológica, conceitual e curricular nos cursos para educação básica e/ou superior, levando em consideração as atividades práticas e teóricas como ferramentas fundamentais para a formação. Essa indicação sinaliza para a importância de atentarmos para um ensino mais aberto e complexo, tal como preconizam as referências da complexidade (GARCIA, 1998, 2004; MORIN, 2007) e reflexividade (BECK; GIDDENBS; LASH, 1997).

Em K4 os autores trazem uma percepção acerca da sustentabilidade pautada na conservação do ecossistema. Ao abordar as percepções de professores e alunos, os resultados em K4 se aproximam dos parâmetros encontrados em K2. Em K2 foram analisados os indicadores gerais, documentos e demais parâmetros que oferecem orientações de como se trabalhar EA no contexto escolar, refletido nas concepções sobre os problemas ambientais. Em $\mathrm{K} 4$ as percepções de professores e alunos sobre EA tendem a reconhecer ações antrópicas como prejudiciais ao meio, e que causam grande parte dos problemas ambientais. Essas percepções também tendem a compreender a importância de uma postura ecológica para o desenvolvimento de uma prática cidadã sustentável, procurando uma perspectiva mais complexa. Do ponto de vista da criticidade freireana, entende-se a prática cidadã como a compreensão do papel dos indivíduos, numa sociedade em constante transformação.

Em K5, também, há uma proximidade aos aspectos da criticidade e reflexividade ao abordar a sustentabilidade e desenvolvimento sustentável com um olhar mais crítico sobre as catástrofes ambientais e a busca pela conscientização ambiental, caminhando em direção às ideias de decrescimento. Em K6 o foco volta-se para a importância da EA reinventar a maneira de lidar e agir no/com o ambiente, considerando as esferas econômica, social, política, cultural e ecológica. Novamente, trata-se de uma perspectiva mais complexa e reflexiva sobre o meio, destacando-se, nessas categorias, a necessidade da compreensão e posicionamento diante das informações abordadas pelos meios de comunicação nos tempos atuais sobre crimes ambientais e/ou vacinas, por exemplo. 


\section{Considerações Finais}

Ao considerar uma Educação para o Risco, construída a partir das reflexões indicadas nas produções da EA, e os referencias teóricos que abordam aspectos da complexidade, do decrescimento e ideias sobre o risco, é possível pensar em formas de atuação no contexto escolar, tanto local quanto globalmente. Identificar os riscos do dia a dia pode proporcionar aos sujeitos outras visões acerca de suas realidades, dando a oportunidade de reconstruírem-se. Quando os riscos são mais globais, trata-se de, por exemplo, compreender as relações que se estabelecem; as aproximações e os distanciamentos que são necessários para entender um problema. Em suma, os riscos dão margem para pensarmos na conexão; na globalização a qual estamos submetidos. Nessa linha, Morin (2020) destaca em suas redes sociais ${ }^{14}$, ao tratar da crise global provocada pelo COVID-19, a necessidade de uma reconstrução social. Para ele, em relação à crise econômica, "o retorno do mundo ao neoliberalismo e a onda tecnoeconômica sob o impulso do lucro desencadeado degradarão novamente a biosfera e as condições da vida humana. Portanto, tem que haver outra economia e outra política"15 (MORIN, 2020, s.p.).

As questões sociais, históricas, políticas e econômicas, atreladas a um sistema que consome, de forma pouco sustentável, os recursos que são finitos são as principais causas dos problemas socioambientais enfrentados hoje; sem a atuação direta da sociedade sobre essas questões torna-se difícil imaginar que caminharemos para um futuro em que as práticas se tornem sustentáveis e os recursos passem a ser utilizados de forma consciente.

Para nós, uma primeira aproximação a essa questão está na escola, especialmente ao tratar do ensino de ciências e as outras esferas do conhecimento. Para que possamos formar sujeitos na perspectiva mais crítica é essencial orientar os docentes por pressupostos que, efetivamente, tenham significado na vida dos sujeitos. Esses significados requerem, por exemplo, que as propostas de aulas promovam discussões mais abertas, nas quais as certezas e os reducionismos sejam analisados e identificados como limitadores em situações que compreendem sistemas dinâmicos e abertos. Em outras palavras, se estamos falando de um problema socioambiental é essencial discutir o planeta Terra como um sistema aberto e dinâmico, e reconhecer que a perspectiva determinista da ciência nos ajuda pontualmente. É preciso reconhecer que a perspectiva da complexidade deve ser ensinada para que os alunos tenham a oportunidade de analisar um problema científico aberto e em construção. E, ainda, que esse problema possa ser visto por outros pontos de vista, o que denotamos como outras esferas do conhecimento.

O desenvolvimento de uma consciência socioambiental no âmbito escolar, pautada por parâmetros que orientem a Educação para o Risco, parece ser uma maneira de contribuir para uma formação mais crítica e complexa. Tal formação requer, como já salientado, considerar as visões de mundo que permeiam a sociedade, sua comunidade e os interesses e as ideias dos alunos sobre um tema tratado. É fundamental que os sujeitos dialoguem e se posicionem frente aos problemas que terão que enfrentar em suas vidas, tomando decisões coerentes que levem a um bem comum, que respeitem os direitos e os deveres de uma nação, que contemplem o direito à vida, e que preservem a democracia.

14 https://twitter.com/edgarmorinparis/status/1248570139156647936 (8:14 AM • Apr 10, 2020·Twitter Web App)

15 Tradução nossa: "La crise économique favorise la biosphère terrienne, le retour mondial au Neo-liberalisme et au déferlement technoeconomique sous l'impulsion du profit déchaînée dégradera à nouveau la biosphère et les conditions de vie humaine. Il faut donc autre économie et autre politique". 


\section{Agradecimentos}

Esse trabalho foi parcialmente financiado pela Fundação de Amparo à Pesquisa do Estado de São Paulo (Fapesp) referente ao processo n ${ }^{\circ}$ 2018/19136-3; a Coordenação de Aperfeiçoamento de Pessoal de Nível Superior (Capes) MCTI /CNPq /MEC/CAPES No440369/2019-3; a bolsa da UFABC/Doutorado é 23006.000123/2018-23 e a bolsa PICUFABC, referente ao Edital 01/2019.

\section{Referências}

BECK, U. Sociedade de Risco. São Paulo: Editora 34, 2010.

BECK, U.; GIDDENS, A.; LASH, S. (Orgs.). Modernização Reflexiva. São Paulo: Editora da Unesp, 1997.

BOFF, O., E.; GOETTEMS, P. B.; DEL PINO, J.C. Ambiente e vida - o ser humano nesse contexto: uma estratégia de ensino transformadora do currículo escolar. Revista eletrônica do Mestrado em Educação Ambiental, Rio Grande, v. 26, [s.n.], p. 306-321, jan./jun. 2011. Disponível em: <https://periodicos.furg.br/remea/article/view/3501/2081>. Acesso em: 24 jan. 2022.

BRASIL. Ministério da Educação. Secretaria de Educação Média. PCNs+ Ensino Médio: Orientações educacionais complementares aos Parâmetros Curriculares Nacionais. Ciências da Natureza, Matemática e suas Tecnologias. Brasília: MEC, 2002.

BRASIL. Ministério da Educação. Secretaria de Educação Média. BNCC - Base Nacional Comum Curricular. Ciências da Natureza, Matemática e suas Tecnologias. Brasília: MEC, 2018.

BUDREVICIUS, T, R. O tema água para discutir a física no ensino médio: as escolhas dos professores em seus percursos temáticos. 2017. 181 f. Dissertação (Mestrado em Ensino, História e Filosofia das Ciências e Matemática) - Universidade Federal do ABC, São Paulo, 2017.

CARVALHO, F. R. As Hipóteses de progressão numa progressão numa proposta de aula complexificada sobre o tema aquecimento global. 2016. 152 f. Dissertação (Mestrado em Ensino, História e Filosofia das Ciências e Matemática) - Universidade Federal do ABC, São Paulo, 2016.

CARVALHO, F.; WATANABE, G; RODRÍGUEZ-MARÍN, F. Os níveis de progressão nas formulações dos alunos frente às questões socioambientais. In: ENCONTRO NACIONAL DE PESQUISA EM EDUCAÇÃO DE CIÊNCIAS, 10, 2015, Águas de Lindóia. Anais... São Paulo: ABRAPEC, 2015. p. 1-8. Disponível em: <http://www.abrapecnet.org.br/enpec/xenpec/anais2015/lista_area_06.htm>. Acesso em 24 jan. 2022.

DELIZOICOV, D.; ANGOTTI, J. A.; PERNAMBUCO, M. M. Ensino de Ciências: fundamentos e métodos. São Paulo: Cortez, 2002.

DIAZ, J. E. G.; WATANABE, G. Menos pode ser mais: do decrescimento e descomplexificação à complexidade. Revista Linhas Críticas, Brasília, v. 25, [s.n.], p. 10-24, jan./dez. 2019. Disponível em <https://periodicos.unb.br/index.php/linhascriticas/article/view/19699/20563>. Acesso em: 24 jan. 2022. 
FREIRE, P. Pedagogia do oprimido. Rio de Janeiro: Paz e Terra, 1977.

GARCÍA, J. E. Hacia una teoría alternativa sobre los contenidos escolares. Madrid: Díada Editora S. L, 1998.

GARCÍA, J. E. Educación ambiental, constructivismo y complejidad. Série Fundamental, n21. Madrid: Díada Editora S. L, 2004.

GUERRERO, F. A.; NIETO, R. M.; HERRUZO, L. R.; LÓPEZ, L. L.; RODRÍGUEZ, M. F. Y.; GARCÍA, D. E. El huerto educativo ante el cambio climático: Propuesta de una hipótesis de transición sobre el agua y la alimentación. Investigación en la Escuela, Sevilla, [s.v], n. 103, p. 48-63. Disponível em <http://dx.doi.org/10.12795/IE.2021.i103.04>. Acesso em: 24 jan. 2022.

JACOBI, P. Educar para a Sustentabilidade: complexidade, reflexividade, desafios. In: Revista Educação e Pesquisa, São Paulo, v. 31, n.2, p. 233-250, maio/ago. 2005. Disponível em <https://www.scielo.br/pdf/ep/v31n2/a07v31n2.pdf>. Acesso em 12 jan. 2020.

LACERDA, N. O. S.; STRIEDER, R. B. Educação CTS e formação de professores: dimensões a serem contempladas a partir do modelo crítico-transformador. Educação e Fronteiras, Dourados, v. 9, [s.n.], p. 110-126, 2019.

LATOUCHE, S. Pequeno tratado do decrescimento sereno. São Paulo: Martins Fontes, 2009.

MORAES, R.; GALIAZZI, M. C. Análise Textual Discursiva. Ijuí: Unijuí, 2007.

MORIN, E. Introdução ao pensamento complexo. 3 ed. Porto Alegre: Sulina, 2007.

MORIN, E. (edgarmorinparis). Status/1248570139156647936. Paris, Apr. 10, 2020. Twitter: @edgarmorinparis. Disponível em:

<https://twitter.com/edgarmorinparis/status/1248570139156647936>. Acesso em: 24 jan. 2022.

MORIN, E. (edgarmorinparis). Status/1241685822107193345. Paris, Mar. 22, 2020. Twitter: @edgarmorinparis. Disponível em:

<https://twitter.com/edgarmorinparis/status/1241685822107193345>. Acesso em: 26 jan. 2022.

PERES, R. B., SCHENK, L. B. M. Planejamento da paisagem e mudanças climáticas: uma abordagem multidisciplinar em São Carlos (SP). Ambiente \& Sociedade, São Paulo, v.24., [s.n.], p. 1-26, 2021.

PETRAGLIA, I. Pensamento complexo e educação. São Paulo: Livraria da Física, 2013.

PRIGOGINE, I.; STENGERS, I. Entre o tempo e a eternidade. São Paulo: Companhia das Letras, 1992.

RERISCO - Educação Pré-Escolar, Ensino Básico (1. ${ }^{\circ} 2^{\circ} .^{\circ}$ e 3. ${ }^{\circ}$ ciclos) e Ensino Secundário. Lisboa: Ministério da Educação e Ciência, 2015.

RODRIGUEZ-MARÍN, F; FERNÁNDEZ-ARROYO, J; GARCÍA, J. Las hipótesis de transición como herramienta didáctica para la educación ambiental. Enseñanza de Las Ciencias, Barcelona, v. 32, n. 3, p. 303-318. Disponível em <http://dx.doi.org/10.5565/rev/ensciencias.1137>. Acesso em: 24 jan. 2022.

SANTOS, C. S., CARVALHO, F., FREITAS, D., WATANABE, G. Um percurso temático complexificado sobre horta: as contribuições das hipóteses de transição. Revista de Educación 
Ambiental y Sostenibilidad, Cádiz, v. 3, n. 2, p. 01-16, 2021. Disponível em:

<https://revistas.uca.es/index.php/REAyS/article/view/7115>. Acesso em: 24 jan. 2022.

TAVARES, A. S. Física Ambiental e teoria da complexidade: inserção de tópicos essenciais da teoria da complexidade no ensino médio - a viabilidade de uma proposta. 2011. 113f. Dissertação (Mestrado em Física Ambiental) - Universidade Federal de Mato Grosso, Cuiabá, 2011.

WATANABE, G. As contribuições dos aspectos da complexidade para um ensino de física mais crítico. Revista Brasileira de Ensino de Física, São Paulo, v. 43, [s.n.], p. e20200416-1/1-e20200416$12,2021$.

WATANABE, G., KAWAMURA, M. R. Uma educação na perspectiva ambiental crítica, complexa e reflexiva. Revista Brasileira de Pesquisa em Educação em Ciências, Rio de Janeiro, v. 14, n. 2, p. 255-264, 2014. Disponível em <https://periodicos.ufmg.br/index.php/rbpec/article/view/4366>. Acesso em 26 jan. 2022. 
Pesquisa em Educação Ambiental, vol. 16, n. 2, 2021 DOI: http://dx.doi.org/10.18675/2177-580X.2021-16508

APÊNDICE 1 


\begin{tabular}{|c|c|c|c|c|}
\hline Categorias & Trabalhos & Título do Trabalho & $\begin{array}{c}\text { Dados da } \\
\text { publicação }\end{array}$ & $\begin{array}{l}\text { Palavras-chave/ } \\
\text { sub-palavras }\end{array}$ \\
\hline \multirow{15}{*}{ K1 } & T62 & $\begin{array}{l}\text { Contribuições da educação ambiental crítica para o processo de ensino e } \\
\text { aprendizagem em ciências visando à formação cidadã }\end{array}$ & 2018 & $\begin{array}{l}\text { Educação ambiental } \\
\text { crítica }\end{array}$ \\
\hline & $\mathrm{T} 76$ & Educação ambiental e preservação do ambiente escolar - & 2018 & Educação ambiental \\
\hline & $\mathrm{T} 77$ & Consumismo como tema de problematização da educação ambiental & 2018 & Educação ambiental. \\
\hline & $\mathrm{T} 78$ & $\begin{array}{l}\text { Gincana ambiental: uma proposta de educação ambiental na rede municipal } \\
\text { de Paraguaçu Paulista - SP }\end{array}$ & 2018 & Educação ambiental, \\
\hline & T86 & $\begin{array}{l}\text { "gota em gota a água se esgota": análise de uma proposta de ensino com o } \\
\text { tema a água - }\end{array}$ & 2018 & Educação ambiental \\
\hline & T88 & Meio ambiente e tecnologias: o uso de QR CODES em aulas de ciências & 2018 & Meio ambiente; \\
\hline & T89 & Agentes da natureza: uma ação de educação ambiental no ensino fundamental & 2018 & Educação ambiental, \\
\hline & T93 & $\begin{array}{l}\text { Educação ambiental crítica: relato de experiência de um minicurso para } \\
\text { profissionais da educação }\end{array}$ & 2018 & Educação ambiental \\
\hline & T97 & A educação ambiental na conformidade da lei: um relato de experiência & 2018 & Educação ambiental, \\
\hline & T103 & $\begin{array}{l}\text { Desenvolvimento e aplicação de uma animação didática sobre educação } \\
\text { ambiental em uma escola no município de messias - al }\end{array}$ & 2018 & Educação ambiental; \\
\hline & T106 & $\begin{array}{l}\text { História em quadrinhos em ciências: uma experiência com educação } \\
\text { ambiental - }\end{array}$ & 2018 & $\begin{array}{l}\text { Educação } \\
\text { ambiental. }\end{array}$ \\
\hline & T163 & $\begin{array}{l}\text { Desenvolvimento e validação do instrumento de alfabetização ambiental para } \\
\text { adolescentes }\end{array}$ & 2018 & $\begin{array}{l}\text { Environmental } \\
\text { education; }\end{array}$ \\
\hline & T164 & $\begin{array}{l}\text { Examinando experiências de aprendizado ambiental em um acampamento de } \\
\text { verão sobre educação terrestre }\end{array}$ & 2018 & $\begin{array}{l}\text { Environmental } \\
\text { education }\end{array}$ \\
\hline & T181 & $\begin{array}{l}\text { Sustainability education in a botanical garden promotes environmental } \\
\text { knowledge, attitudes and willingness to act }\end{array}$ & 2018 & $\begin{array}{l}\text { Environmental } \\
\text { education }\end{array}$ \\
\hline & T206 & $\begin{array}{l}\text { Argumentação de alunos da primeira série do Ensino Médio sobre o tema } \\
\text { "Energia": discussões numa perspectiva de Educação Ambiental. }\end{array}$ & 2018 & Educação ambiental; \\
\hline \multirow{3}{*}{$\mathrm{K} 2$} & T147 & $\begin{array}{l}\text { O uso de indicadores para avaliação qualitativa de projetos educativos } \\
\text { socioambientais: a gestão participativa no ambiente escolar }\end{array}$ & 2019 & $\begin{array}{l}\text { Desenvolvimento } \\
\text { socioambiental; }\end{array}$ \\
\hline & T208 & $\begin{array}{l}\text { Políticas públicas de educação ambiental e processos de mediação em escolas } \\
\text { de Ensino Fundamental. }\end{array}$ & 2018 & Educação ambiental; \\
\hline & T209 & $\begin{array}{l}\text { Aspectos da complexidade nas questões socioambientais: as abordagens no } \\
\text { Brasil e na Espanha. }\end{array}$ & 2018 & Educação ambiental \\
\hline \multirow{9}{*}{ K3 } & $\mathrm{T} 2$ & $\begin{array}{l}\text { La educación para la sostenibilidad en la formación del profesorado de } \\
\text { ciencias experimentales en secundaria }\end{array}$ & 2019 & $\begin{array}{c}\text { Educación para la } \\
\text { sostenibilidad }\end{array}$ \\
\hline & $\mathrm{T} 3$ & $\begin{array}{l}\text { Evaluación de las competencias ambientales del profesorado de primaria en } \\
\text { formación inicial: estudio de caso }\end{array}$ & 2018 & Educación ambiental \\
\hline & T31 & $\begin{array}{l}\text { Transposição do rio São Francisco - o uso da controvérsia controlada como } \\
\text { meio de promover aproximações entre o enfoque educacional CTS e educação } \\
\text { ambiental crítica }\end{array}$ & 2018 & $\begin{array}{l}\text { Educação ambiental } \\
\text { crítica }\end{array}$ \\
\hline & T92 & $\begin{array}{l}\text { Projeto de extensão o futuro é agora: atividades de educação ambiental na } \\
\text { faculdade de formação de professores da UERJ, na visão dos seus bolsistas - }\end{array}$ & 2018 & Educação ambiental, \\
\hline & T197 & $\begin{array}{l}\text { A Pesquisa-ação na formação continuada em Educação Ambiental para } \\
\text { professores de matemática }\end{array}$ & 2019 & Educação ambiental \\
\hline & T99 & $\begin{array}{l}\text { A disciplinarização da educação ambiental no curso de licenciatura em } \\
\text { ciências biológicas da UFES - campus São Mateus: reflexões }\end{array}$ & 2018 & Meio ambiente, \\
\hline & T105 & $\begin{array}{l}\text { Permacultura e currículo: aproximações possíveis por meio da prática como } \\
\text { componente curricular na formação de professores de biologia }\end{array}$ & 2018 & Permacultura \\
\hline & T107 & $\begin{array}{l}\text { Ensino de ciências da natureza em educação ambiental aplicado em dois } \\
\text { projetos de extensão do instituto federal de São Paulo junto à escola pública - }\end{array}$ & 2018 & Educação ambiental \\
\hline & T207 & $\begin{array}{l}\text { Formação de professores em educação ambiental crítica centrada na } \\
\text { investigação-ação e na parceria colaborativa. }\end{array}$ & 2018 & $\begin{array}{l}\text { Educação ambiental } \\
\text { crítica; }\end{array}$ \\
\hline
\end{tabular}




\begin{tabular}{|c|c|c|c|c|}
\hline \multirow{16}{*}{$\mathrm{K} 4$} & $\mathrm{~T} 1$ & $\begin{array}{l}\text { Competencias para mejorar la argumentación y la toma de decisiones sobre } \\
\text { conservación de la biodiversidad }\end{array}$ & 2019 & $\begin{array}{l}\text { Biodiversidade } \\
\text { educación ambiental }\end{array}$ \\
\hline & T191 & $\begin{array}{l}\text { Aspectos da educação ambiental crítica no ensino fundamental por meio de } \\
\text { atividades de modelagem matemática. }\end{array}$ & 2019 & Meio ambiente. \\
\hline & T198 & $\begin{array}{l}\text { Percepções de universitários sobre as mudanças climáticas e seus impactos: } \\
\text { estudo de caso no Distrito Federal. }\end{array}$ & 2019 & $\begin{array}{l}\text { Educação ambiental; } \\
\text { Meio ambiente }\end{array}$ \\
\hline & T199 & $\begin{array}{l}\text { Transformação para a sustentabilidade e seus elementos promotores nas } \\
\text { instituições de ensino: um estudo de caso em uma instituição focada na } \\
\text { aprendizagem transformadora. }\end{array}$ & 2019 & Sustentabilidade \\
\hline & $\mathrm{T} 200$ & $\begin{array}{l}\text { Uma abordagem sistêmica da sustentabilidade - a interconexão de suas } \\
\text { dimensões nas práticas das ecovilas. }\end{array}$ & 2019 & Sustentabilidade \\
\hline & $\mathrm{T} 4$ & $\begin{array}{l}\text { Análisis de la percepción de la educación para la sostenibilidad por parte del } \\
\text { profesorado de Educación Secundaria y Bachillerato }\end{array}$ & 2018 & $\begin{array}{l}\text { Educación para la } \\
\text { sostenibilidad }\end{array}$ \\
\hline & $\mathrm{T} 30$ & $\begin{array}{l}\text { Contribuições da educação ambiental crítica para o processo de ensino e } \\
\text { aprendizagem em ciências visando à formação cidadã }\end{array}$ & 2018 & $\begin{array}{l}\text { Educação Ambiental } \\
\text { Crítica, Meio } \\
\text { Ambiente }\end{array}$ \\
\hline & T82 & $\begin{array}{l}\text { Percepção dos discentes de escolas de ensino médio sobre os impactos } \\
\text { ambientais no cerrado, no município de Chapadinha-MA }\end{array}$ & 2018 & Meio ambiente \\
\hline & T90 & $\begin{array}{l}\text { A educação ambiental por meio da literatura de cordel no ensino do lixo e } \\
\text { meio ambiente }\end{array}$ & 2018 & $\begin{array}{l}\text { Educação ambiental, } \\
\text { meio ambiente. }\end{array}$ \\
\hline & T100 & $\begin{array}{l}\text { Literatura em aulas de biologia: sensilização e abordagem de questões } \\
\text { ambientais por meio da literatura adulta de monteiro lobato }\end{array}$ & 2018 & Educação ambiental \\
\hline & T102 & $\begin{array}{l}\text { Concepções docentes sobre as ciências da natureza nas atividades de } \\
\text { educação ambiental: uma questão de centralidade? }\end{array}$ & 2018 & Educação ambiental \\
\hline & T104 & É ecologia ou educação ambiental professora? & 2018 & Educação ambiental, \\
\hline & T166 & $\begin{array}{|lcccc|}\text { "Nós } & \text { vimos } & \text { o } & \text { Abibe" } & \text { praticando } \\
\text { cidadania ambiental na Educação Cientifica do ensino médio } & & \\
\end{array}$ & 2018 & $\begin{array}{l}\text { Environmental } \\
\text { education; }\end{array}$ \\
\hline & $\mathrm{T} 223$ & $\begin{array}{l}\text { Paradigmas da educação ambiental: análise das percepções e práticas de } \\
\text { professores de uma rede pública de ensino }\end{array}$ & 2018 & Educação ambiental. \\
\hline & $\mathrm{T} 201$ & $\begin{array}{l}\text { Vivências de Protagonismo Socioambiental por Jovens: Implicações na } \\
\text { Constituição do Sujeito Ético-Político }\end{array}$ & 2018 & $\begin{array}{l}\text { Meio ambiente; } \\
\text { Educação ambiental }\end{array}$ \\
\hline & T194 & $\begin{array}{l}\text { Sustentabilidade ambiental em Instituições de Ensino Superior, um estudo } \\
\text { bibliométrico sobre as publicações nacionais }\end{array}$ & 2019 & Práticas ambientais. \\
\hline \multirow{9}{*}{ K5 } & $\mathrm{T} 29$ & $\begin{array}{l}\text { Educação ambiental na formação inicial docente: um mapeamento das } \\
\text { pesquisas brasileiras em teses e dissertações }\end{array}$ & 2019 & Educação ambiental \\
\hline & T178 & $\begin{array}{l}\text { Social mapping and environmental education: dialogues from participatory } \\
\text { mapping in the Pantanal, Mato Grosso, Brazil }\end{array}$ & 2019 & $\begin{array}{l}\text { Environmental } \\
\text { education; }\end{array}$ \\
\hline & $\mathrm{T} 83$ & $\begin{array}{l}\text { Pesquisas em sustentabilidade na educação ambiental: um retrato da } \\
\text { desigualdade no brasil }\end{array}$ & 2018 & $\begin{array}{l}\text { Desenvolvimento } \\
\text { sustentável }\end{array}$ \\
\hline & T95 & Educação ambiental: não temos tempo a perder? & 2018 & Meio ambiente; \\
\hline & T96 & $\begin{array}{l}\text { Green Day: pensando a educação ambiental fora da caixinha no CEFET/RJ } \\
\text { campus maria da graça }\end{array}$ & 2018 & $\begin{array}{l}\text { Desenvolvimento } \\
\text { sustentável; }\end{array}$ \\
\hline & $\mathrm{T} 202$ & A educação ambiental na educação infantil segundo os saberes de Morin & 2018 & Educação ambiental \\
\hline & T179 & $\begin{array}{l}\text { Environmental and sustainability education in the Benelux countries: } \\
\text { research, policy and practices at the intersection of education and societal } \\
\text { transformation }\end{array}$ & 2018 & $\begin{array}{l}\text { Environmental and } \\
\text { sustainability } \\
\text { education; }\end{array}$ \\
\hline & $\mathrm{T} 210$ & $\begin{array}{l}\text { Possíveis confluências filosóficas e pedagógicas entre a educação ambiental } \\
\text { crítica e a pedagogia histórico-crítica. }\end{array}$ & 2018 & Educação ambiental \\
\hline & $\mathrm{T} 224$ & $\begin{array}{l}\text { Contribuição de metodologias participativas como prática mediadora em } \\
\text { educação química e ambiental }\end{array}$ & 2018 & Educação ambiental. \\
\hline \multirow{2}{*}{ K6 } & $\mathrm{T} 74$ & $\begin{array}{l}\text { Documentários ambientais: contribuições para a sensibilização ambiental no } \\
\text { ensino superior }\end{array}$ & 2018 & Meio ambiente. \\
\hline & $\mathrm{T} 81$ & $\begin{array}{l}\text { Antropocentrismo nos livros didáticos de biologia: uma reflexão sobre } \\
\text { educação ambiental e relações humano-natureza. }\end{array}$ & 2018 & Educação ambiental \\
\hline
\end{tabular}

